Bioedusiana

Vol. 02, No. 01, Sep 2017

ISSN $2477-5193$

\title{
PENGARUH PRE TEST TERHADAP TINGKAT PEMAHAMAN MAHASISWA CALON GURU BIOLOGI PADA MATERI PRAKTIKUM PEWARNAAN GRAM MATA KULIAH MIROBIOLOGI
}

\author{
Vita Meylani ${ }^{1)}$, dan Suharsono ${ }^{1)}$ \\ ${ }^{1}$ Jurusan Pedidikan Biologi Fakultas Keguruan dan Ilmu Pendidikan \\ Universitas Siliwangi Tasikmalaya \\ Jl. Siliwangi No. 24 Kota Tasikmalaya 46115 \\ Email: meylani.vita@yahoo.co.id
}

\begin{abstract}
The research was aimed to determine the effect of pre-test of the level of understanding of student teachers in the material Biology Practical Course Gram Microbiology. Five classes of the population of the three classes of samples taken at random, two classes into one class experimental and control classes. Two experimental classes were treated pretest sbelum following study microbiology courses on gram staining material, whereas the untreated control class. Our results showed that there were significant differences between the control and experimental class classes against gram-level understanding of the material. It is based on the difference in the average yield post-test which differ significantly, supported by the results of statistical analysis. In addition, the results of pre-test and post-test in the experimental class has a considerable range of scores.
\end{abstract}

Key words : Pre-test, Microbiology, Gram Staining

\begin{abstract}
ABSTRAK
Penelitian ini bertujuan untuk mengetahui pengaruh pre-test terhadap tingkat pemahaman guru siswa di Materi Biologi Praktikum Gram Mikrobiologi. Lima kelas populasi dari tiga kelas sampel diambil secara acak, dua kelas menjadi satu kelas kelas eksperimen dan kontrol. Dua kelas eksperimen diobati dengan pretest sbelum mengikuti studi mikrobiologi pada bahan pewarnaan gram, sedangkan kelas kontrol yang tidak diobati. Hasil kami menunjukkan bahwa ada perbedaan yang signifikan antara kelas kontrol dan kelas eksperimen terhadap pemahaman tingkat gram material. Hal ini didasarkan pada perbedaan rata-rata hasil post-test yang berbeda secara signifikan, didukung oleh hasil analisis statistik. Selain itu, hasil pre-test dan post-test di kelas eksperimen memiliki nilai skor yang cukup banyak.
\end{abstract}

Kata Kunci : Pre-test, Mikrobiologi, Pewarnaan Gram 


\section{PENDAHULUAN}

Praktikum merupakan bagian terpenting dalam mempelajari Biologi pada umumnya tidak terkecuali Mikrobiologi sebagai salah satu cabang Biologi. Mata kuliah Mikrobiologi sering dianggap sebagai sesuatu yang kurang memiliki peran penting dalam penguasaan Biologi secara keseluruhan terutama oleh mahasiswa Pendidikan Biologi. Hal tersebut disebabkan karena kajian Mikrobiologi sedikit sekali ditemui pada materi sekolah baik sekolah Menengah Pertama maupun Sekolah Menengah Atas. Padahal Mikrobiologi merupakan bagian terpenting dari Biologi bahkan dalam kehidupan manusia. Hal tersebut juga didukung dengan sejajarnya cabang ilmu Mikrobiologi dengan Botani dan Zoologi.

Pada saat Praktikum biasanya jarang dilakukan penekanan pemahaman materi yang akan dipraktikumkan dengan dukungan teori yang teah disampaikan sebelumnya. Hal ini menyebabkan mahasiswa hanya mengerjakan prakikum sesuai petunjuk yang ada pada buku penuntun praktikum tanpa memahami maksud, tujuan, kegunaan alat dan bahan, serta dasar teori praktikum tersebut. Oleh karena itu, mahasiswa seringkali tidak mengerti dengan apa yang mereka lakukan pada saat praktikum. Sehingga perlu dilakukan sebuah tes untuk mengetahui tingkat pemahaman mahasiswa mengenai materi praktikum yang dilakukan di awal praktikum (pre test).

Materi praktikum pewarnaan gram merupakan salah satu materi inti pada mata kuliah Mikrobiologi. Akan tetapi, materi ini seringkali kurang dapat dipahami oleh mahasiswa disebabkan oleh beberapa faktor, antara lain (i) adanya miskonsepsi pemahaman mengenai pewarnaan gram, dan (ii) kurang dapat dipahaminya materi mengenai struktur sel bakteri sebagai dasar karakter kunci pewarnaan gram. Hal tersebut juga didukung berdasarkan kenyataan di lapangan hasil penilaian praktikum pada materi Pewarnaan gram nilainya paling rendah dibandingkan acara praktikum yang lain.

\section{METODE PENELITIAN}

Metode penelitian yang digunakan dalam penelitian ini adalah metode eksperimen semu (quasi-experimental). Perlakuan yang digunakan dalam penelitian ini adalah pemberian pre test pada saat acara praktikum.

\section{HASIL DAN PEMBAHASAN}

Kelas eksperimen dalam penelitian ini sebanyak 2 kelas (A dan B) mengikuti pembelajaran mata kuliah Mikrobiologi pada materi pewarnaan gram dengan di awali pre test sedangkan yang 1 kelas kontrol (C) tidak mendapatkan perlakuan pre test. Akan tetapi, ketiga kelas mendapat perlakuan yang sama di akhir pembelajaran 
(post test). Hasil pre test kelas eksperimen (Gambar 1).

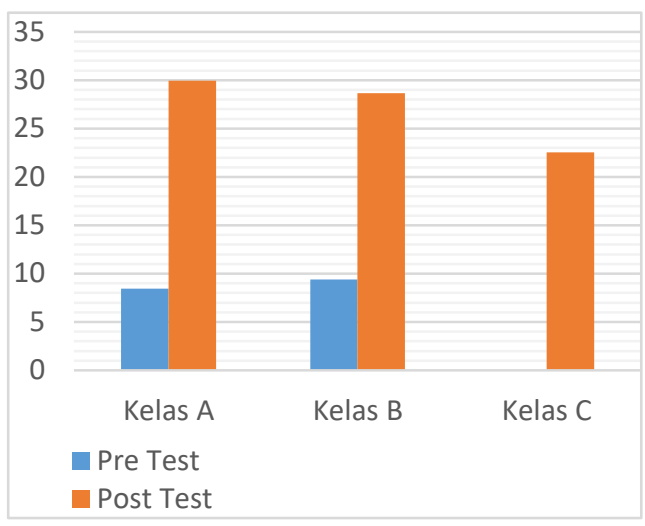

Gambar 1. Grafik Hasil Pre test dan Post test

Data di atas diperoleh berdasarkan hasil pre test sebanyak 40 soal. Hasil di atas tersebut menunjukkan masih rendahnya pemahaman mahasiswa mengenai materi yang akan disampaikan dalam hal ini pewarnaan gram. Dari 40 soal yang diberikan ada yang dapat menajawab lebih dari $60 \%$ jawaban benar yang menunjukkan tingkat pemahamannya cukup baik. Hasil tersebut dapat dipengaruhi oleh beberapa faktor yaitu faktor internal dan ekternal (Slameto 2009:54). Sehingga masing-masing mahasiswa memiliki kemampuan yang berbeda dalam menjawab soal pre test tersebut.

Hasil pre test pada kelas eksperimen menunjukkan bahwa mahasiswa belum memahami konsep materi pewarnaan gram. Meskipun demikian, pemberian pre test dapat memotivasi mahasiswa untuk mempersiapkan diri sebelum pembelajaran, sehingga siswa lebih aktif selama proses pembelajaran (Ibrahim 2003:130). Hal ini dikarenakan hasil pre test yang kurang memuaskan dapat membuat mahasiswa termotivasi untuk dapat lebih memahami materi yang akan disampaikan oleh dosen. Hal ini dibuktikan dengan perbedaan hasil post test pada kelas eksperimen (Tabel 1).

\begin{tabular}{lcc}
\multicolumn{3}{c}{ Tabel 1. Rata-rata Skor Pre Tes Kelas Eksperimen } \\
\hline No. & Nama & Skor Rata-rata \\
\hline 1. & Kelas Eksperimen A & 8,4 \\
2. & Kelas Eksperimen B & 9,6 \\
\hline
\end{tabular}

Hasil di atas menunjukkan rerata yang signifikan antara hasil pre test dan post test yang dapat diasumsikan sebagai adanya peningkatan pemahaman mahasiswa terhadap materi pewarnaan gram. Keberhasilan tersebut tidak terlepas dari beberapa faktor yang dimungkinkan mempengaruhi hasil belajar mahasiswa antara lain (i) kemampuan mahasiswa, penjelasan materi, (iii) waktu yang tersedia untuk belajar, lingkungan, dan (v) pengalaman (Sudjana, Nana 2009: 39). Selain itu faktor intern (motivasi) siswa untuk memahami materi setelah memperoleh hasil pre test menjadi salah satu hal yang tidak dapat diabaikan dalam keberhasilan hasil belajar mahasiswa dalam bentuk tingkat pemahaman yang meningkat. Hasil post test kelas eksperimen memiliki rerata yang lebih tinggi 
Tabel 2. Rata-rata Skor Post Test Kelas Eksperimen dan kelas Kontrol

\begin{tabular}{llc}
\hline No. & \multicolumn{1}{c}{ Nama } & Skor Rata-rata \\
\hline 1. & Kelas Eksperimen A & 29,9 \\
2. & Kelas Eksperimen B & 28,7 \\
3. & Kelas Kontrol C & 22,5 \\
\hline
\end{tabular}

Hasil post test pada kelas kontrol menunjukkan hasil yang kurang memuaskan dan jauh dari rerata hasil post test pada kelas eksperimen. Hal ini menunjukkan bahwa perlakuan pre test memberikan pengaruh positif terhadap tingkat pemahaman mahasiswa. Hasil tersebut didukung pula oleh hasil pengolahan data secara statistik yang menunjukkan bahwa hasil post test pada kedua kelas berbeda secara signifikan.

Pre test merupakan alat evaluasi tentang bahan yang akan diajarkan pada saat itu kepada siswa/mahasiswa (Romayulis, 2005: 21). Pada penelitian ini, pre test diberikan pada dua kelas eksperimen yang kemudian pada akhir pembelajaran diberikan post test. Pre test bertujuan untuk mengetahui rumusan tujuan yang akan dicapai dalam proses pembelajaran sehingga dengan mengadakan pre test guru/dosen dapat mengetahui kondisi siswa/mahasiswa tentang pengetahuan dan keterampilan sebelum proses pembelajaran dengan mempedomani hasil test yang diperoleh (Romayulis, 2005: 21). Di sisi lain, Sudijono (2008:30), menjelaskan bahwa dengan adanya pemberian pre test akan memotivasi siswa untuk mempersiapkan diri dengan artian belajar sebelum proses pembelajaran berlangsung di sekolah. Dengan adanya persiapan tersebut, maka siswa akan lebih memahami materi pelajaran yang diberikan. Hal tersebut dibuktikan dengan hasil penelitian yang menunjukkan adanya perbedaan hasil post test yang signifikan antara kelas eksperimen dengan kelas kontrol (1 dan 2).

Pewarnaan gram atau pewarnaan diferensial (differential stain) yaitu pewarnaan yang menggunakan lebih dari satu macam zat warna. Pewarnaan gram merupakan merupakan salah satu materi dalam mata kuliah Mikrobiologi yang dianggap kurang dapat dipahami oleh mahasiswa. Pada materi ini mahasiswa di harapkan dapat mencapai beberapa kemampuan baik kognitif maupun psikomotor. Hal ini, ditunjukkan dengan adanya peningkatan pemahaman mengenai materi pewarnaan gram terutama pada kelas kontrol (Tabel 1 dan Tabel 2) yang diasumsikan karena adanya pengaruh pre test.

Pemahaman terhadap suatu konsep pembelajaran merupakan hasil konstruksi atau rekonstruksi 
terhadap objek-objek pembelajaran (Suparno, 1997). Konstruksi atau rekonstruksi tersebut dilakukan melalui aktivitas berupa aksi-aksi, proses-proses, objek-objek yang diorganisasikan dalam suatu skema untuk memecahkan suatu permasalahan (Dubinsky, 2000; DeVries, 2001). Pemahaman juga diartikan sebagai pengertian yang mendalam (Depdikbud, 1988: 636). Sedangkan Mrozek (2000) menyatakan, pemahaman merupakan suatu proses memahami arti/makna tertentu dan kemampuan menggunakannya pada situasi lainnya.

Tingkat pemahaman adalah tingkat kemampuan seseorang yang mampu memahami arti atau konsep, situasi serta fakta yang diketahuinya. Dalam hal ini, tidak hanya hapal secara verbalitas, tetapi memahami konsep dari masalah atau fakta yang ditanyakan. Secara kognitif pemahaman dapat dibagi menjadi tiga aspek yaitu translasi, interpretasi, dan ekstrapolasi yang dapat dioptimalkan melalui keberanian mengungkapkan pendapat tentang materi yang disampaikan guru atau temannya.

Berdasarkan uraian di atas dapat disimpulkan terdapat pengaruh pre test terhadap tingkat pemahaman mahasiswa calon guru Biologi pada materi praktikum pewarnaan gram mata kuliah Mikrobiologi.

\section{SIMPULAN}

Berdasarkan hasil penelitian dapat disimpulkan bahwa terdapat pengaruh pre test terhadap tingkat pemahaman mahasiswa calon guru Biologi pada materi pewarnaan gram mata kuliah Mikrobiologi. Hal terebut didasarkan berdasarkan data hasil post test pada kelas eksperimen dan kelas kontrol yang didukung oleh data statistik.

\section{DAFTAR PUSTAKA}

Alexander, Steve K., Strete Dennis., \& Niles, Mary Jane. (2007).

Laboratory Exercises in Organismal and Molecular Microbiology. New York : Mc Graw Hill Higher Education.

Anderson, O.W., \& D.R Krathwol. (2001). $\underline{A}$ Taxonomy For Learning, Teaching and Assesing. Addison Wesley Longman Inc., New York.

Apriadi, Robby., Hendri, Wince., \& Muhar, Nawir. 2013. Pengaruh Pemberian Pre-test dalam Penerapan Model Pembelajaran Kooperatif Tipe STAD terhadap Hasil Belajar Biologi Kelas X SMAN 1 Jujuhan Kabupaten Bungo.

Arikunto, Suharsimi. 2006. Dasardasar Evaluasi Pendidikan (Edisi Revisi). Jakarta: PT. Bumi Aksara.

Ibrahim, Muslimin. 2003. Pengantar Evaluasi Pendidikan. Jakarta : Bumi Aksara.

Madigan, Michael., Martinko, John., Stahl, David., \& Clark, David. 2012. Brock Biology of Microorganism. San Francisco: Pearson Education, Inc. Benjamin Cummings.

Prescott, Harley. 2002. Laboratory Exercises in Microbiology Fifth 
Edition. New York : Mc Graw Hill Higher Education.

Ramayulis. 2005. Metodologi Pendidikan Agama Islam. Jakarta: Kalam Mulia

Sadiman, Arief. 2003. Media Pendidikan Pengertian,

Pengembangan, dan

Pemanfaatannya. Jakarta:

Pustekom Dikbud dan Raja Grafindo Persada.

Santosa, Pasya Padjar., and Mustofa, Romy Faisal. 2006. Penuntun Praktikum

Mikrobiologi.

Tasikmalaya: Universitas Siliwangi.

Slameto. 2003. Belajar dan Faktorfaktor yang Mempengaruhinya. Jakarta: PT. Rineka Cipta.

Sudijono, Anas. 2008. Pengantar Evaluasi Pendidikan. Jakarta : Raja Grafindo Persada.
Sudjana, Nana. 2009. Dasar-Dasar Proses Belajar Mengajar. Bandung: Sinar Baru Algensindo Suparno, P. 1997. Filsafat Konstruktivisme Dalam Pendidikan. Yogyakarta: Kanisius.

Tri Suharni, Theresia., Natti, Sri Juni., and Soetarto, Endang Sutariningsih. 2008. Mikrobiologi Umum. Yogyakarta: Universitas 